\title{
Wpływ składu mieszanin NiCrBSiFe+WSC i NiBSi+WSC na ich mikrostrukturę i twardość
}

\author{
Influence composition of mixtures NiCrBSiFe+WSC \\ and NiBSi+WSC on their microstructure and hardness
}

\section{Streszczenie}

Powłoki nanoszone metodą lutowania infiltracyjnego charakteryzują się wysoką odpornością na zużycie ścierne oraz dużą twardością. Z racji na wysoką komplikację nanoszenia powłok, postanowiono wykonać wstępne próby na drodze spiekania ziaren węglikowych z fazą ciekłą. Przeprowadzone badania miały na celu wstępne rozpoznanie różnic pomiędzy proszkami NiCrBSiFe a NiBSi w kontekście mikrostruktur i twardości otrzymanych kompozytów. Posłużyły one do zaplanowania koncepcji dalszej pracy badawczej. Projekt prowadzony był we współpracy z firmą AGRO// SELNET.

Słowa kluczowe: NiCrBSiFe; NiBSi; mikrostruktura

\begin{abstract}
Infiltration brazed coatings are characterized by high wear resistance and high hardness. Because of the high complexity of coating process, it was decided to perform the initial samples by sintering the carbide grains with a liquid phase. The study aimed to initial recognition of the differences between NiCrBSiFe and NiBSi alloys in the context of the microstructure and hardness of the composites. These were used to plan the concept of further research. The project was performed in cooperation with AGRO//SELNET Company.
\end{abstract}

Keywords: NiCrBSiFe; NiBSi; microstructure

\section{Wstęp}

Lutowanie infiltracyjne (ang. infiltration brazing) zostało opracowane $w$ latach 70 . XX wieku, jako metoda nanoszenia powłok odpornych na zużywanie ścierne. Półproduktem (tzw. prekompozytem) wykorzystywanym do przeprowadzenia procesu sa elastyczne maty, zawierające proszek metaliczny i dodatek politetrafluoroetylenu (PTFE). Polimer ten jest stosowany w ilości od 1 do $15 \%$ masowych [1]. Poniżej temperatury topnienia stopu lutowniczego PTFE rozkłada się i ulatnia, nie biorąc udziału w procesie lutowania.

Struktury powstałe w wyniku procesu lutowania infiltracyjnego charakteryzują się wysoką twardością i odpornością na ścieranie mineralne, dzięki czemu ten proces może być stosowany do wytwarzania warstw powierzchniowych elementów maszyn takich, jak łożyska, turbiny, cyklony lub brony do pługów. Zastosowanie kompozytowych mat węglikowych, charakteryzujących się dobrą plastycznością, pozwala na przeprowadzenie procesu lutowania infiltracyjnego in situ, co znacznie ułatwiła prace konserwacyjne w przypadku podzespołów wielkogabarytowych bądź wyjątkowo trudnych do demontażu.

Na podstawie przeprowadzonych badań wstępnych oraz porównania ich z dostępną wiedzą teoretyczną sformułowano wnioski i przeprowadzono obserwacje, które mogą okazać się pomocne podczas analizy wpływu określonych para- metrów procesu lutowania infiltracyjnego na mikrostrukturę i wybrane własności mieszanek stopów lutowniczych i węglika wolframu.

\section{Cel i zakres badań}

Celem badań było określenie wpływu składu chemicznego spoiwa lutowniczego na mikrostrukturę próbek powstałych po spiekaniu ziaren węglikowych z fazą ciekłą stopów lutowniczych NiCrBSiFe oraz NiBSi.

Do badań przy użyciu metod mikroskopii świetlnej wykorzystano mikroskop świetlny Nikon Eclipse MA200 z oprogramowaniem NIS Elements BR. Obserwacje były prowadzone przy powiększeniach z zakresu x100 do x2000. Pomiary porowatości wykonano na zgładach, metodą planimetryczną. Do rejestrowania obrazów metodami mikroskopii elektronowej wykorzystano mikroskop skaningowy Jeol JSM-6610A. Obrazy mikrostruktur powierzchni zgładu metalograficznego rejestrowano przy pomocy detektora elektronów rozproszonych wstecznie BSE, w trybie kontrastu materiałowego. Pomiary twardości wykonano metodą Vickersa przy użyciu mikrotwardościomierza MMT-X3 zgodnie z PN-EN ISO 6507-1:2007, pod obciążeniem 9,807 N. Czas trwania obciążenia wynosił $15 \mathrm{~s}$.

Mgr inż. Andrzej Żak, mgr inż. Konrad Sawras, prof. dr hab. inż. Włodzimierz Dudziński- Politechnika Wrocławska. Autor korespondencyjny/Corresponding author. andrzej.zak@pwr.edu.pl 


\section{Materiały do badań}

Materiałami wykorzystanymi podczas badań były proszki stopów lutowniczych (rys. 1A, 1B) oraz topiony węglik wolframu WSC (rys. 1C), dostarczone przez firmę AGRO//SELNET. WSC (niem. Wolframschmelzkarbid) jest mieszaniną eutektyczną węglików wolframu WC oraz W2C. Proszki te, w porównaniu z innymi węglikami, wykazują dobrą zwilżalność ciekłymi metalami [3]. Skład chemiczny substratów wykorzystanych w badaniach zestawiono w tablicy I.

\section{Wyniki badań}

Próbki proszków stopów lutowniczych NiCrBSiFe, NiBSi oraz mieszanek A i B poddano przetopieniu poprzez podgrzanie do temperatury $1250^{\circ} \mathrm{C}$, wytrzymanie w tej temperaturze przez 30 minut oraz schłodzenie do temperatury otoczenia wraz z piecem. Atmosferę 5\% H2 + 95\% N2 utrzymywano W piecu do osiągnięcia podczas chłodzenia temperatury $300{ }^{\circ} \mathrm{C}$. Pozostały proces chłodzenia przebiegał na powietrzu.

Stop NiCrBSiFe wykazał niewielką mikroporowatość oraz strukturę złożoną z trzech faz, których analiza strukturalna będzie przedmiotem dalszych badań (rys. 2). Stop NiBSi nie wykazał porowatości, a jego dwufazowa struktura była częściowo dendrytyczna (rys. 3).

Mieszanki A i B, lutowane w atmosferze 5\% H2 + 95\% N2 wykazały występowanie istotnych różnic. Struktura powstała z mieszanki A (NiCrBSiFe-WSC) o zawartości 40\% węglika WSC (rys. 4) charakteryzuje się mniejszą porowatością od mieszanki B (NiBSi-WSC), zawierającej $60 \%$ węglika WSC (rys. 5), co wstępnie potwierdza zależność wzrostu porowatości mieszanek wraz ze wzrostem zawartości procentowej węglika wolframu. Celem potwierdzenia wyników należy jednak rozszerzyć eksperyment o testy mieszanki A o zawartości $60 \%$ węglika WSC oraz o mieszanki B o zawartości $40 \%$ WSC.

W mieszance A (NiCrBSiFe-WSC) zaobserwowano występowanie fazy przejściowej na granicach węglik-osnowa (rys. 4). Zaobserwowano również częściową dezintegrację ziaren proszku WSC i penetrację fazy ciekłej. Według danych literaturowych uwarunkowane jest to dobrą zwilżalnością ziaren WSC przez stop na bazie Ni [6]. Mikrostruktura próbki NiBSi-WSC charakteryzuje się występowaniem wyraźnej granicy między-

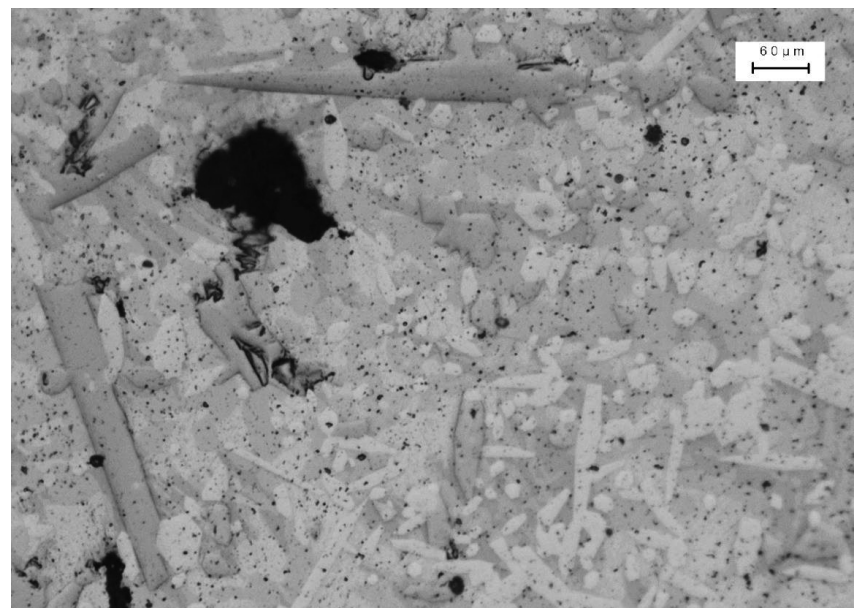

Rys. 2. Mikrostruktura stopu NiCrBSiFe poddanego przetopieniu w atmosferze $5 \%$ wodoru w azocie. Widoczna porowatość oraz złożona struktura wielofazowa. Mikroskopia świetlna.

Fig. 2. Microstructure of the NiCrBSi sintered in $5 \% \mathrm{H} 2,95 \% \mathrm{~N} 2$ atmosphere. The apparent porosity and complex multiphase structure. Light microscopy.

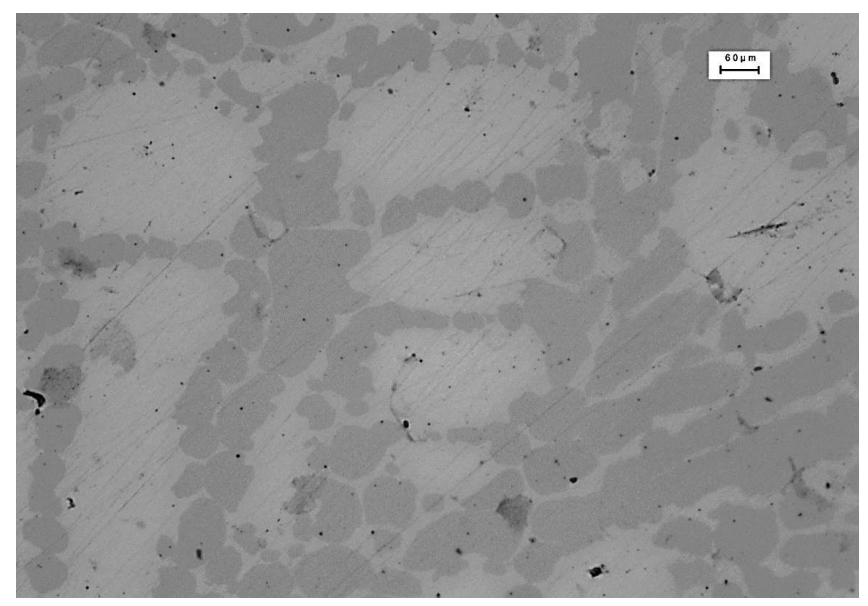

Rys. 3. Mikrostruktura stopu NiBSi poddanego przetopieniu w atmosferze $5 \%$ wodoru w azocie. Widoczna struktura dendrytyczna oraz brak makroskopowej porowatości. Mikroskopia świetlna.

Fig. 3. Microstructure of the NiBSi sintered in 5\% H2, 95\% N2 atmosphere. Visible dendritic structure and the absence of macroscopic porosity. Light microscopy.
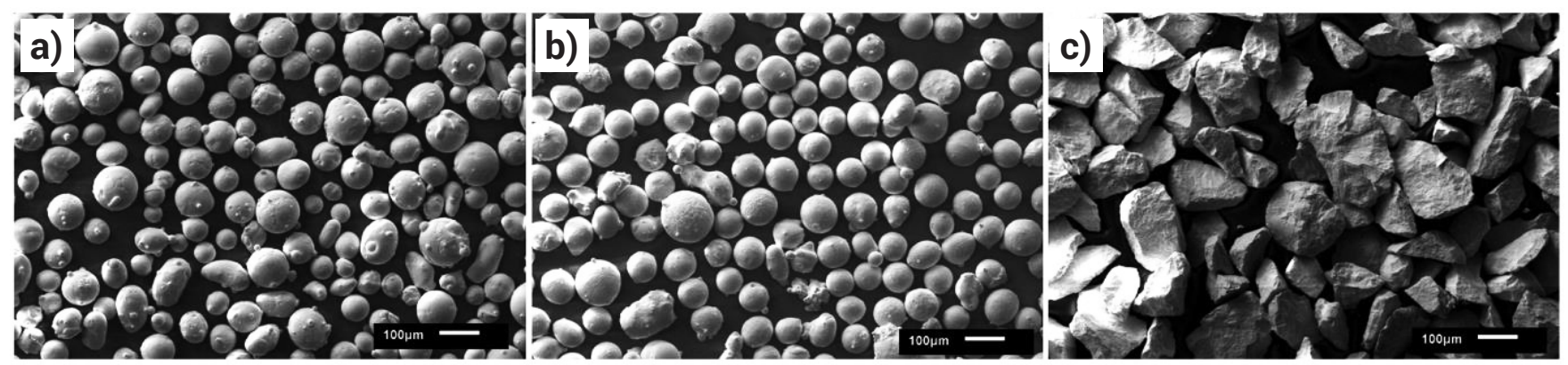

Rys. 1. Obraz proszków: A - NiCrBSiFe, B - NiBSi i C - WSC, SEM

Fig. 1. Image of the powders: A - NiCrBSiFe, B - NiBSi, C - WSC, SEM.

Tablica I. Skład chemiczny stosowanych proszków stopów lutowniczych oraz mieszanek stopów lutowniczych z dodatkiem proszku węglika wolframu WSC

Table I. Chemical composition of the used braze alloys and mixtures of the braze alloy and WSC

\begin{tabular}{|c|c|c|c|c|c|c|c|c|c|c|}
\hline \multirow{2}{*}{ Typ proszku } & \multicolumn{10}{|c|}{ Masowa zawartość \% } \\
\hline & C & $\mathrm{Si}$ & Mn & $\mathbf{P}$ & $\mathrm{S}$ & $\mathrm{Cr}$ & B & $\mathrm{Fe}$ & $\mathrm{Ni}$ & W \\
\hline NiCrBSiFe & 0,88 & 4,41 & 0,04 & $<0,001$ & 0,007 & 15,4 & 2,97 & 3,38 & reszta & - \\
\hline $\mathrm{NiBSi}$ & 0,03 & 3,10 & - & $<0,001$ & 0,003 & - & 3,01 & 0,015 & reszta & - \\
\hline WSC & 4,50 & - & - & - & - & - & - & - & - & reszta \\
\hline
\end{tabular}


fazowej pomiędzy węglikami, a osnową niklową, bez występowania dodatkowej fazy międzymetalicznej (rys. 5).

Celem oceny jakości i użyteczności otrzymanych próbek, wykonano pomiary twardości metodą Vickersa (HV1). Wyniki zestawiono w tablicy II. Najwyższą twardością, sięgającą lokalnie powyżej $1000 \mathrm{HV1}$, charakteryzowała się mieszanka A, składająca się z proszków NiCrBSiFe i WSC. Mieszanka B wykazała niższą twardość, rzędu 500-600 HV1, wynikającą z własności zastosowanego stopu lutowniczego. Spowodowane jest to faktem, że stop NiBSi charakteryzuje się niższą twardością niż stop NiCrBSiFe (odpowiednio 336 i 639 HV1). Duży rozrzut pomiarów wykonanych dla mieszanek A i B spowodowany był występującą porowatością Docelowo należy rozważyć badanie twardości metodą uśredniającą pomiar z większego obszaru zgładu (HV10 lub HB). Należy jednak zaznaczyć, że nie twardość, a odporność na zużywanie

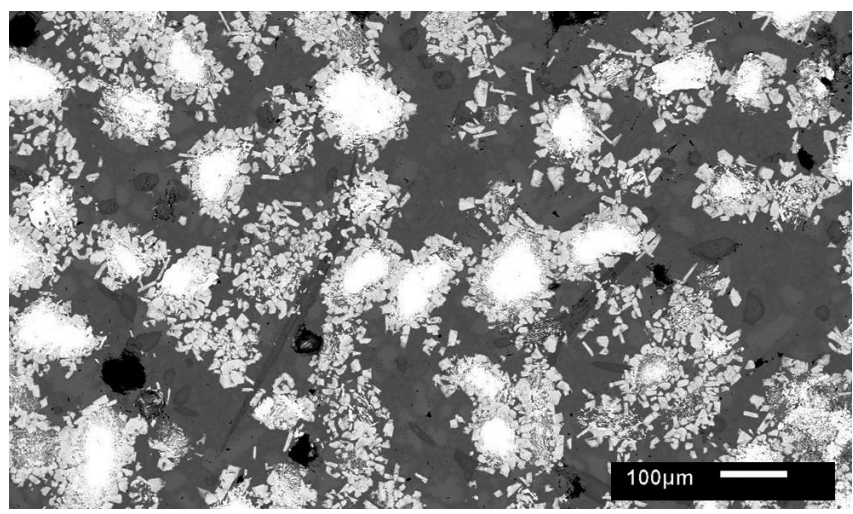

Rys. 4. Mikrostruktura mieszanki A (NiCrBSiFe-WSC). Jasne obszary reprezentują częściowo rozpuszczone w osnowie węgliki wolframu. Wokół węglików wolframu widoczne kryształy nieciągłej fazy przejściowej. SEM, kontrast materiałowy.

Fig. 4. The microstructure of a mixture of A (NiCrBSiFe-WSC). The bright areas represent partially dissolved in the matrix of tungsten carbide. Around the tungsten carbide visible crystals discontinuous phase transition. SEM, material contrast. ścierne powinna być najbardziej istotnym parametrem podczas porównywania wyżej opisanych materiałów.

Tablica II. Wyniki pomiarów twardości próbek Table II. Results of hardness measurements of samples

\begin{tabular}{|c|c|c|c|c|c|}
\hline \multirow{2}{*}{ Nazwa próbki } & \multicolumn{5}{|c|}{ Pomiary twardości HV1 } \\
\cline { 2 - 6 } & $\mathbf{1}$ & $\mathbf{2}$ & $\mathbf{3}$ & $\mathbf{4}$ & $\mathbf{5}$ \\
\hline Mieszanka A & 1081 & 564 & 886 & 1443 & 549 \\
\hline Mieszanka B & 278 & 679 & 577 & 708 & 590 \\
\hline NiCrBSiFe & 695 & 704 & 611 & 532 & 654 \\
\hline NiBSi & 300 & 367 & 319 & 363 & 333 \\
\hline
\end{tabular}

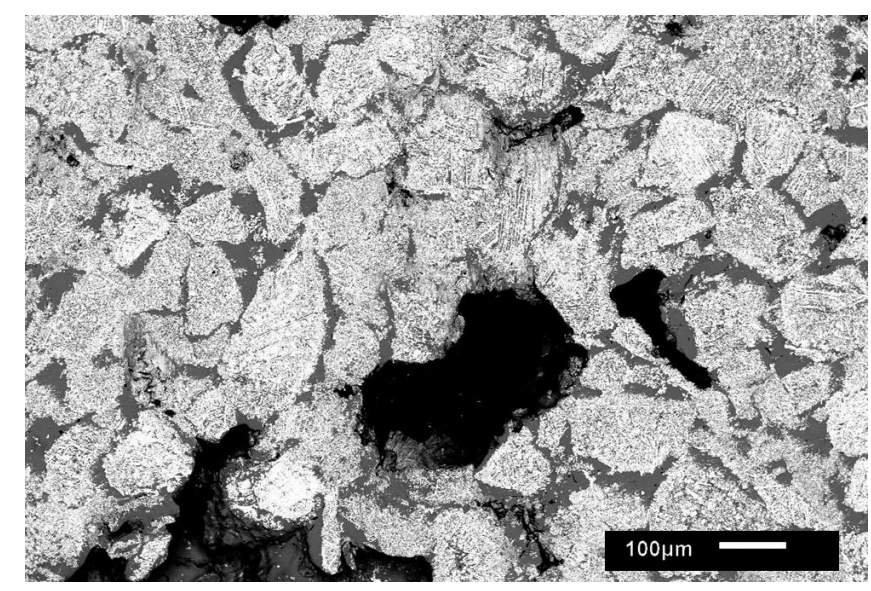

Rys. 5. Mikrostruktura mieszanki B (NiBSi-WSC). Widoczne liczne pory (czarne obszary) oraz niewielka ilość spoiwa lutowniczego (szare obszary). SEM, kontrast materiałowy.

Fig. 5. Microstructure mix B (NiBSi-WSC). Visible plurality of pores (black areas), and a small amount of braze filler (gray areas). SEM, material contrast.

\section{Podsumowanie}

Na podstawie analizy wyników przeprowadzonych badań stwierdzono, że:

- Jest możliwe uzyskanie mieszaniny stopu lutowniczego oraz węglika wolframu w atmosferze 5\% H2 + 95\% N2, jednak przedstawia to większe problemy technologiczne, niż zastosowanie czystego wodoru.

- Zastosowanie mieszaniny NiCrBSiFe+WSC pozwoliło na uzyskanie kompozytu o wyższej twardości niż w przypadku mieszaniny NiBSi+WSC.

- Stop NiCrBSiFe poddany przetopieniu w atmosferze 5\% H2 + 95\% N2 wykazuje dwa razy wyższą twardość niż stop NiBSi.

- Mikrostruktura powłok wykonanych z mieszanki proszku lutowniczego NiCrBSiFe z proszkiem węglikowym WSC charakteryzowała się występowaniem fazy przejściowej na granicy faz węglik-osnowa, podczas gdy w powłoce NiBSi-WSC faza przejściowa nie została zarejestrowana dla zastosowanych parametrów wytwarzania.

- Dla kompozytu NiCrBSiFe+WSC zaobserwowano dezintegrację ziaren WSC i infiltrację fazy ciekłej wewnątrz eutektyki węglikowej.

\section{Literatura}

[1] Coating metallic substrate with powdered filler and molten metal, US Patent $\mathrm{nr}$ 3743556, 1973

[2] Tobar M.J., Alvarez C., Amado J.M., Rodriguez G., Yanez A.: Morphology and characterization of laser clad composite NiCrBSi-WC coatings on stainless steel, Surface \& Coating Technology, 200 (2006) 6313-6317.

[3] Fernandes C.M., Senos A.M.R.: Cemented carbide chase diagrams: A review, Elsevier B.V., 2011.

[4] Schwartz M.: Brazing, 2nd Edition, ASM International, 2003.

[5] Senkara J.: Sterowanie energią adhezji pomiędzy molibdenem i wolframem a ciekłymi metalami w procesach spajania, Wydawnictwa Politechniki Warszawskiej, Warszawa 1993.
[6] Senkara J., Windyga A.: Podstawy teorii procesów spajania, Wydawnictwa Politechniki Warszawskiej, Warszawa 1990.

[7] Morel S.: Powłoki dla ochrony przed zużyciem elementów maszyn i urządzeń, w: Przegląd Spawalnictwa, Vol. 87, No 9 (2015).

[8] Kondej A., Babul T.: Mikrostruktura natapianej powłoki Ni-Cr-B-Si, Przegląd Spawalnictwa Vol 88, No 3 (2016).

[9] Broda T., Keitel S.: Resistance seam hardfacing and cladding of WC-Co in a NiCrBSi-Matrix, w: Przegląd Spawalnictwa, Vol 88, No 3 (2016) 